\title{
Polymerization of $t$-Butylacetylene by Group 6 Transition Metal Catalysts: Geometric Structure Control by Reaction Conditions*
}

\author{
Yoshimichi OKano, Toshio MASUdA, and Toshinobu HIGASHIMURA \\ Department of Polymer Chemistry, Kyoto University, \\ Kyoto 606, Japan.
}

(Received January 30, 1982)

\begin{abstract}
The geometric structure of poly( $t$-butylacetylene) could be controlled by the choice of suitable polymerization conditions (solvents and catalysts): $t$-Butylacetylene was polymerized in high yield by $\mathrm{MoCl}_{5}$ and $\mathrm{WCl}_{6}$ in oxygen- or nitrogen-containing solvents (e.g., anisole, acetophenone, benzonitrile and nitrobenzene). The molecular weights of the polymers formed were as high as $5 \times 10^{4}-2 \times 10^{5}$. According to ${ }^{13} \mathrm{C} \mathrm{NMR}$, polymers prepared in nonpolar solvents like toluene comprised comparable amounts of cis and trans structures. On the other hand, polymers obtained with $\mathrm{MoCl}_{5}$ in oxygen- or nitrogen-containing solvents possessed the cis structure exclusively. The mechanism of geometric structure control was discussed.

KEY WORDS $t$-Butylacetylene / Coordination Polymerization / Molybdenum Pentachloride / Tungsten Hexachloride / Polyene / Geometric Structure / ${ }^{13} \mathrm{C}$ Nuclear Magnetic Resonance / Metal Carbene /
\end{abstract}

Polymers obtained from acetylene and its derivatives possess conjugated double bonds along the main chain. The geometric isomerism of the main chain in these polymers is an important problem, since it will have great influence on polymer properties. Both all-cis and all-trans polyacetylenes have been successfully synthesized with a Ziegler catalyst, $\mathrm{Ti}(\mathrm{O} n \mathrm{Bu})_{4}-\mathrm{Et}_{3} \mathrm{Al}$, by the choice of proper polymerization temperature and catalyst composition. ${ }^{2}$

On the other hand, only a few reports have appeared on the geometric structure control of other acetylenic polymers: Polymers from arylacetylenes like phenylacetylene have been obtained under various polymerization conditions and their geometric structure have been qualitatively estimated by several research groups. ${ }^{3-5}$ In contrast, the geometric isomerism of polymers from aliphatic acetylenes has hardly been elucidated.

The purpose of the present study is to control the geometric structure of polymer by choice of solvents and catalysts in the polymerization of an aliphatic acetylene. $t$-Butylacetylene was employed as a monomer, since its bulky $t$-butyl group would contribute to the selective formation of a particular geometric structure. $t$-Butylacetylene can be polymerized by $\mathrm{MoCl}_{5}$ and $\mathrm{WCl}_{6}$ in hydrocarbons and halogenated hydrocarbons to afford a highmolecular-weight polymer in high yield, and the geometric structure of the main chain can be determined by ${ }^{13} \mathrm{C}$ NMR spectroscopy. ${ }^{6}$ Quite recently, a ${ }^{13} \mathrm{C}$ NMR spectrum of poly $(t$-butylacetylene) has also been reported by Katz et al.,$^{7}$ but no discussion was made regarding its geometric structure on the basis of the spectrum. We thus studied extensively the geometric structure of poly ( $t$-butylacetylene) prepared under a variety of reaction conditions. Consequently, perfectly cis poly ( $t$-butylacetylene) was obtained in quantitative yield with $\mathrm{MoCl}_{5}$ catalyst.

\section{EXPERIMENTAL}

$t$-Butylacetylene was prepared from pinacolone according to the literature method. ${ }^{8,9} \mathrm{MoCl}_{5}, \mathrm{WCl}_{6}$,

\footnotetext{
* Polymerization of Aliphatic Acetylenes. Part V. For Part 4, see ref 1.
} 
$\mathrm{Mo}(\mathrm{CO})_{6}$, and $\mathrm{W}(\mathrm{CO})_{6}$ were commercially obtained. Solvents for polymerization (reagent grade) were distilled twice before use from appropriate drying agents at atmospheric or reduced pressure under nitrogen.

Polymerization was carried out under a dry nitrogen atmosphere at $30^{\circ} \mathrm{C}$ for $24 \mathrm{~h}$ at a monomer concentration of $1.0 \mathrm{moll}^{-1}$ and a catalyst concentration of $30 \mathrm{mmoll}^{-1}\left(\mathrm{MoCl}_{5}, \mathrm{WCl}_{6}\right)$ or 10 $\mathrm{mmoll}^{-1}\left(\mathrm{Mo}(\mathrm{CO})_{6}, \mathrm{~W}(\mathrm{CO})_{6}\right)$. When tetraphenyltin $\left(\mathrm{Ph}_{4} \mathrm{Sn}\right)$ was employed as cocatalyst, catalyst solutions were aged at $30^{\circ} \mathrm{C}$ for $20 \mathrm{~min}$ before use. A solution of metal carbonyl in carbon tetrachloride was irradiated with UV light ( $200 \mathrm{~W}$ high pressure $\mathrm{Hg}$ lamp) at $30^{\circ} \mathrm{C}$ for $1 \mathrm{~h}$ (this catalyst expressed as $\left.\mathrm{M}(\mathrm{CO})_{6}-\mathrm{CCl}_{4}-h v(\mathrm{M}=\mathrm{Mo}, \mathrm{W})\right)$. To the irradiated catalyst solution was added a monomer solution in the dark, and polymerization was run at $30^{\circ} \mathrm{C}$ for $24 \mathrm{~h}$. The polymer formed was precipitated into a large amount of methanol, filtered off, and dried under vacuum. Polymer yields were determined by gravimetry.

Intrinsic viscosities, $[\eta]$, of polymers were measured in toluene at $30^{\circ} \mathrm{C}$. Molecular weights $(M)$ were calculated from viscosities using eq (1) obtained in our previous study ${ }^{6}$ :

$$
[\eta]=10^{-5.12} \times M^{1.01} \quad\left(\mathrm{dl} \mathrm{g}^{-1}\right)
$$

${ }^{13} \mathrm{C}$ NMR spectra were recorded in $\mathrm{CDCl}_{3}$ so- lution ( $c a .15 \mathrm{w} / \mathrm{v} \%)$ at room temperature on a JNM FX90Q spectrometer operating at $22.50 \mathrm{MHz}$ under complete proton noise-decoupling. Accumulation of $2000-4000$ scans was made using approximately a $45^{\circ}$ pulse repeated every $2.0 \mathrm{~s}$. Overlapping methyl carbon signals were separated with a du Pont 310 curve resolver.

\section{RESULTS AND DISCUSSION}

\section{Polymerization under Various Conditions - Yield and} Molecular Weight of Polymer

Table I shows the results for the polymerization of $t$-butylacetylene by $\mathrm{MoCl}_{5}$ and $\mathrm{WCl}_{6}$ in oxygencontaining solvents such as ethers, esters, and ketones. These solvents are seemingly unfavorable, because they may coordinate to catalyst metals to reduce catalytic activity and also because they are nonsolvents of poly(t-butylacetylene). Contrary to such expectation, $t$-butylacetylene was polymerized in high yields in these solvents. In general, the polymer yield was higher with $\mathrm{MoCl}_{5}$ than with $\mathrm{WCl}_{6}$, and in aromatic solvents than in aliphatic solvents. The molecular weights of the polymers reached $5 \times 10^{4}-2 \times 10^{5}$, which are comparable to those attained in hydrocarbons and halogenated hydrocarbons. ${ }^{6}$ Generally, $\mathrm{MoCl}_{5}$ provided higher molecular weights than did $\mathrm{WCl}_{6}$.

The polymerization by $\mathrm{MoCl}_{5}$ took place even in

Table I. Polymerization of $t$-butylacetylene by $\mathrm{MoCl}_{5}$ and $\mathrm{WCl}_{6}$ in oxygen-containing solvents ${ }^{\mathrm{a}}$

\begin{tabular}{|c|c|c|c|c|c|c|}
\hline \multirow{2}{*}{ No. } & \multirow{2}{*}{ Catalyst } & \multirow{2}{*}{ Solvent } & \multirow{2}{*}{$\begin{array}{c}\text { Polymer yield } \\
\%\end{array}$} & \multirow{2}{*}{$\frac{[\eta]^{\mathrm{b}}}{\mathrm{dl} \mathrm{g}^{-1}}$} & \multirow{2}{*}{$\bar{M} \times 10^{-3}$} & \multirow{2}{*}{$\frac{{ }^{13} \mathrm{C} \text { NMR, } \delta}{32.4: 31.2}$} \\
\hline & & & & & & \\
\hline 1 & $\mathrm{MoCl}_{5}$ & 1,2-Dimethoxyethane & 100 & 1.63 & 190 & $0: 100$ \\
\hline 2 & $\mathrm{MoCl}_{5}$ & Anisole & 100 & 1.69 & 197 & $0: 100$ \\
\hline 3 & $\mathrm{MoCl}_{5}$ & Ethyl acetate & 55 & 1.78 & 208 & $0: 100$ \\
\hline 4 & $\mathrm{MoCl}_{5}$ & Methyl benzoate & 100 & 1.60 & 186 & $0: 100$ \\
\hline 5 & $\mathrm{MoCl}_{5}$ & Acetone & 21 & 0.98 & 115 & $0: 100$ \\
\hline 6 & $\mathrm{MoCl}_{5}$ & Acetophenone & 100 & 1.47 & 171 & $0: 100$ \\
\hline 7 & $\mathrm{WCl}_{6}$ & 1,2-Dimethoxyethane & 54 & 0.85 & 100 & 3: 97 \\
\hline 8 & $\mathrm{WCl}_{6}$ & Anisole & 82 & 0.48 & 57 & $21: 79$ \\
\hline 9 & $\mathrm{WCl}_{6}$ & Ethyl acetate & 70 & 1.04 & 122 & 2: 98 \\
\hline 10 & $\mathrm{WCl}_{6}$ & Methyl benzoate & 42 & 0.92 & 108 & 3: 97 \\
\hline 11 & $\mathrm{WCl}_{6}$ & Acetone & 30 & 0.40 & 47 & 5: 95 \\
\hline 12 & $\mathrm{WCl}_{6}$ & Acetophenone & 53 & 0.41 & 48 & 9: 91 \\
\hline
\end{tabular}

a Polymerized at $30^{\circ} \mathrm{C}$ for $24 \mathrm{~h} ;[\mathrm{M}]_{0}=1.0 \mathrm{~mol} \mathrm{l}^{-1}$, $[\mathrm{Cat}]=30 \mathrm{mmol} \mathrm{l}^{-1}$.

b Measured in toluene at $30^{\circ} \mathrm{C}$. 
Table II. Polymerization of $t$-butylacetylene by $\mathrm{MoCl}_{5}$ in nitrogen-containing solvents ${ }^{\mathbf{a}}$

\begin{tabular}{|c|c|c|c|c|c|c|}
\hline \multirow{2}{*}{ No. } & \multirow{2}{*}{ Catalyst } & \multirow{2}{*}{ Solvent } & \multirow{2}{*}{$\frac{\text { Polymer yield }}{\%}$} & \multirow{2}{*}{$\frac{[\eta]^{\mathrm{b}}}{\mathrm{dl} \mathrm{g}^{-1}}$} & \multirow{2}{*}{$\bar{M} \times 10^{-3}$} & \multirow{2}{*}{$\frac{{ }^{13} \mathrm{C} \mathrm{NMR}, \delta}{32.4: 31.2}$} \\
\hline & & & & & & \\
\hline 1 & $\mathrm{MoCl}_{5}$ & Acetonitrile & 7 & - & - & $0: 100$ \\
\hline 2 & $\mathrm{MoCl}_{5}$ & Benzonitrile & 90 & 1.60 & 186 & $0: 100$ \\
\hline 3 & $\mathrm{MoCl}_{5}$ & Nitroethane & 2 & - & - & - \\
\hline 4 & $\mathrm{MoCl}_{5}$ & Nitrobenzene & 36 & 0.84 & 98 & $3: 97$ \\
\hline 5 & $\mathrm{MoCl}_{5} \cdot \mathrm{Ph}_{4} \mathrm{Sn}$ & Acetonitrile & 48 & - & - & $0: 100$ \\
\hline 6 & $\mathrm{MoCl}_{5} \cdot \mathrm{Ph}_{4} \mathrm{Sn}$ & Benzonitrile & 100 & 1.76 & 205 & $0: 100$ \\
\hline 7 & $\mathrm{MoCl}_{5} \cdot \mathrm{Ph}_{4} \mathrm{Sn}$ & Nitroethane & 43 & - & - & $0: 100$ \\
\hline 8 & $\mathrm{MoCl}_{5} \cdot \mathrm{Ph}_{4} \mathrm{Sn}$ & Nitrobenzene & 63 & 1.27 & 148 & $0: 100$ \\
\hline
\end{tabular}

a Polymerized at $30^{\circ} \mathrm{C}$ for $24 \mathrm{~h} ;[\mathrm{M}]_{0}=1.0 \mathrm{~mol} \mathrm{l}^{-1}$, $[\mathrm{Cat}]=30 \mathrm{mmoll}^{-1}$.

b Measured in toluene at $30^{\circ} \mathrm{C}$.

Table III. Polymerization of $t$-butylacetylene by $\mathrm{M}(\mathrm{CO})_{6}-\mathrm{CCl}_{4}-h v(\mathrm{M}=\mathrm{Mo}, \mathrm{W})^{\mathrm{a}}$

\begin{tabular}{|c|c|c|c|c|c|c|}
\hline \multirow{2}{*}{ No. } & \multirow{2}{*}{ Metal carbonyl } & \multirow{2}{*}{$\frac{\text { Temp }}{{ }^{\circ} \mathrm{C}}$} & \multirow{2}{*}{$\frac{\text { Polymer yield }}{\%}$} & \multirow{2}{*}{$\frac{[\eta]^{\mathrm{b}}}{\mathrm{dl} \mathrm{g}^{-1}}$} & \multirow{2}{*}{$\bar{M} \times 10^{-3}$} & \multirow{2}{*}{$\frac{{ }^{13} \mathrm{C} \mathrm{NMR}, \delta}{32.4: 31.2}$} \\
\hline & & & & & & \\
\hline 1 & $\mathrm{Mo}(\mathrm{CO})_{6}$ & 30 & 100 & 2.60 & 292 & $14: 86$ \\
\hline 2 & $\mathrm{Mo}(\mathrm{CO})_{6}$ & 0 & 95 & 2.26 & 263 & $12: 88$ \\
\hline 3 & $\mathrm{~W}(\mathrm{CO})_{6}$ & 30 & 92 & 1.54 & 180 & $20: 80$ \\
\hline
\end{tabular}

a Polymerized in $\mathrm{CCl}_{4}$ at $30^{\circ} \mathrm{C}$ for $24 \mathrm{~h}$ : $[\mathrm{M}]_{0}=1.0 \mathrm{~mol} \mathrm{l}^{-1},\left[\mathrm{M}(\mathrm{CO})_{6}\right]=10 \mathrm{mmol} \mathrm{l}^{-1}$.

b Measured in toluene at $30^{\circ} \mathrm{C}$.

nitrogen-containing solvents such as nitriles and nitro compounds (Table II), although they should coordinate to the catalyst more strongly than oxygen-containing solvents. Polymer yields increased considerably in the presence of $\mathrm{Ph}_{4} \mathrm{Sn}$ cocatalyst (equimolar to $\mathrm{MoCl}_{5}$ ), as observed in the polymerization of phenylacetylene. ${ }^{10}$ In contrast, $\mathrm{WCl}_{6}$ afforded hardly any polymers either in the presence or absence of $\mathrm{Ph}_{4} \mathrm{Sn}$ in the nitrogencontaining solvents.

No polymerization occurred when such solvents were used as dimethyl sulfoxide, $N, N$-dimethylformamide, pyridine, and acetic acid, probably because these solvents coordinate strongly to catalysts to form inactive complexes or react with catalysts to decompose them.

The kind of ligands on a catalyst is expected to have a large influence, both sterically and electroni- cally, on the behavior of the catalyst. Thus, polymerization of $t$-butylacetylene was carried out in carbon tetrachloride using the $\mathrm{M}(\mathrm{CO})_{6}-\mathrm{CCl}_{4}-h v$ catalysts $(\mathrm{M}=\mathrm{Mo}, \mathrm{W})$. These catalysts have been used for olefin metathesis ${ }^{11}$ and the polymerization of certain acetylenic monomers. ${ }^{12}$ As shown in Table III, the metal carbonyl catalysts polymerized $t$ butylacetylene almost quantitatively. The polymer molecular weights were higher than those obtained with the corresponding metal chlorides in the same solvent ( $c f . M=11 \times 10^{4}$ with $\mathrm{MoCl}_{5}, 9.2 \times 10^{4}$ with $\left.\mathrm{WCl}_{6}\right){ }^{6}$

Poly( $t$-butylacetylene)s obtained in hydrocarbons and halogenated hydrocarbons dissolve readily in nonpolar solvents such as hexane and toluene. ${ }^{6}$ Transparent films can be prepared from these polymer solutions. On the other hand, some of the polymers obtained in oxygen- or nitrogen- 
containing solvents were partly insoluble and gave translucent films. This might be due to partial crystallinity of the polymers, although no sharp crystalline $\mathrm{X}$-ray diffraction patterns were observed.

\section{Geometric Structure of Polymer}

${ }^{13} \mathrm{C} N M R$ Analysis. Figure 1 shows the ${ }^{13} \mathrm{C}$ NMR spectrum of poly( $t$-butylacetylene) obtained with $\mathrm{WCl}_{6}$ in toluene. Two well-resolved methyl signals are seen at $31.2\left(a_{1}\right)$ and $32.4\left(a_{2}\right)$ ppm, as previously reported. ${ }^{6}$ The areas of signals $a_{1}$ and $a_{2}$ are comparable. On the other hand, the polymer formed with $\mathrm{MoCl}_{5}$ in anisole shows only $a_{1}$ (Figure 2). It should also be noted that ali the signals of the latter

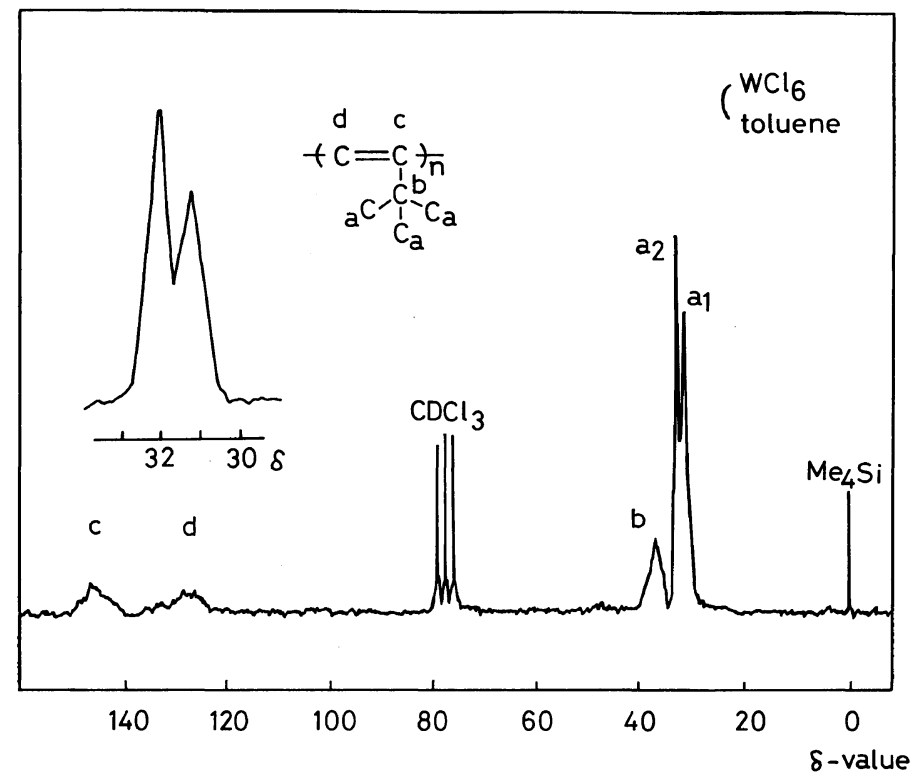

Figure 1. ${ }^{13} \mathrm{C}$ NMR spectrum of poly(t-butylacetylene). (sample from Table IV, No. $1, \mathrm{WCl}_{6}$ )

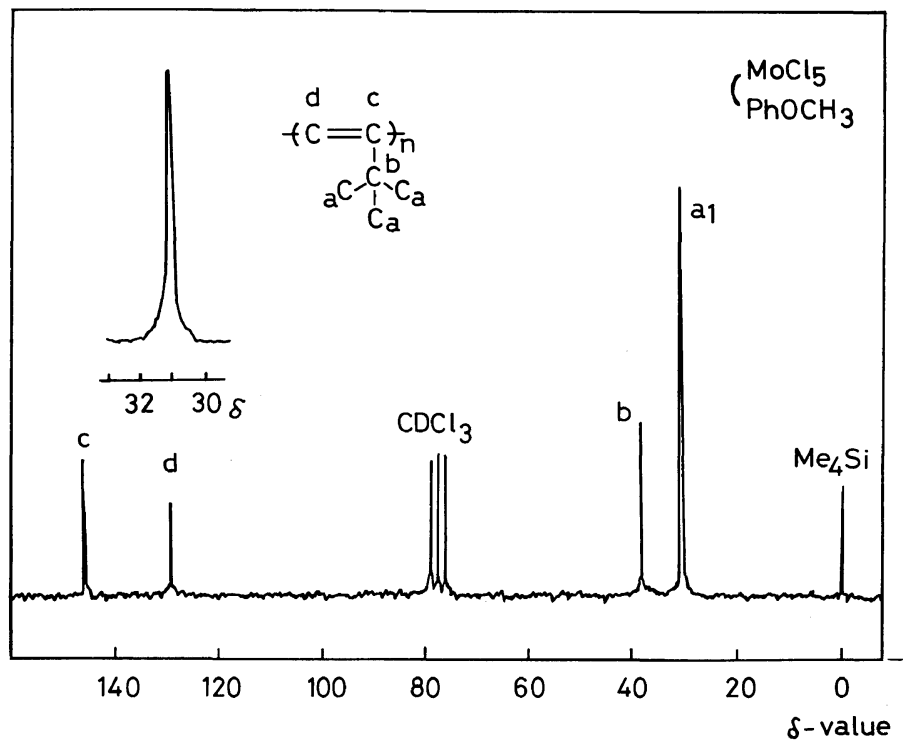

Figure 2. ${ }^{13} \mathrm{C}$ NMR spectrum of poly( $t$-butylacetylene). (sample from Table I, No. 2) 
polymer are very sharp.

It seems reasonable to attribute $a_{1}$ to $c i s$ and $a_{2}$ to the trans structure of the polymer backbone for the following reasons: i) The relative intensity of peak $a_{1}$ to $a_{2}$ is greater with $\mathrm{MoCl}_{5}$ than with $\mathrm{WCl}_{6}$ for polymers prepared otherwise under the same conditions. Provided that, as for poly(arylacetylenes), ${ }^{5,13} \quad \mathrm{MoCl}_{5}$ gives poly( $t$-butylacetylene) having higher $c i s$ content than does $\mathrm{WCl}_{6}$, then $a_{1}$ can be attributed to the cis structure. ii) Polymers whose $a_{1}$ and $a_{2}$ are similar in magnitude show a broad $\alpha$ carbon signal (b) centered at $37.1 \mathrm{ppm}$ (see Figure 1), whereas polymers having only $a_{1}$ exhibit a sharp $\alpha$ carbon signal at $38.2 \mathrm{ppm}$ (see Figure 2). In the case of retinal and its congeners, which have conjugated double bonds, the cis isomers show a signal due to $\alpha$ carbon at lower field than do the corresponding trans isomers. ${ }^{14}$ In this analogy, $a_{1}$ is attributed to cis structure. iii) The above assignment of $a_{1}$ and $a_{2}$ is supported by CNDO molecular orbital calculation. ${ }^{15}$

Effect of Solvents and Catalysts. Tables I-III include relative areas of $a_{2}$ and $a_{1}$ signals. These relative areas directly indicate the trans-to-cis ratios according to the above peak assignment. For comparison, ratios for the polymers prepared in hydrocarbons and halogenated hydrocarbons ${ }^{6}$ are given in Table IV.

Polymers formed in nonpolar solvents such as toluene consist of both trans and cis structures; in particular, the trans and cis contents are about the same when $\mathrm{WCl}_{6}$ is used as the catalyst. Thus, the polymerization in nonpolar solvents lacks the selec-

Table IV. Ratios of methyl carbon signals in the ${ }^{13} \mathrm{C}$ NMR spectra of poly $(t \text {-butylacetylene })^{\mathrm{a}}$

\begin{tabular}{llll}
\hline & & \multicolumn{2}{c}{${ }^{13} \mathrm{C} \mathrm{NMR}, \delta$} \\
\cline { 3 - 4 } No. & \multirow{2}{*}{ Solvent } & \multicolumn{2}{c}{$32.4: 31.2$} \\
\cline { 3 - 4 } & & $\mathrm{MoCl}_{5}$ & $\mathrm{WCl}_{6}$ \\
\hline \multirow{2}{*}{1} & Toluene & $24: 76$ & $50: 50$ \\
2 & Cyclohexane & $15: 85$ & $50: 50$ \\
3 & $\mathrm{CCl}_{4}$ & $26: 74$ & $45: 55$ \\
4 & $\left(\mathrm{CH}_{2} \mathrm{Cl}\right)_{2}$ & $14: 86$ & $23: 77$ \\
\hline
\end{tabular}

a Polymerization conditions: $[\mathrm{M}]_{0}=1.0 \mathrm{~mol} \mathrm{l}^{-1}$, [Cat $]=$ $20 \mathrm{mmol}^{-1}, 30^{\circ} \mathrm{C}, 24 \mathrm{~h}$. See ref 6 for polymer yields and molecular weights. tivity for geometric structure. On the other hand, the polymers produced with $\mathrm{MoCl}_{5}$ in oxygencontaining solvents possess exclusively the cis structure (see Table I). Similarly, the use of oxygencontaining solvents increases the cis content appreciably in the $\mathrm{WCl}_{6}$-catalyzed polymerization. All-cis polymers are also formed with $\mathrm{MoCl}_{5}$ $\left(\cdot \mathrm{Ph}_{4} \mathrm{Sn}\right)$ in nitrogen-containing solvents (see Table II). The poly( $t$-butylacetylene) prepared with a tungsten carbene, $\mathrm{Ph}\left(\mathrm{CH}_{3} \mathrm{O}\right) \mathrm{C}=\mathrm{W}(\mathrm{CO})_{5}$ by Katz et al. appears to comprise mostly cis structure according to the reported ${ }^{13} \mathrm{C}$ NMR spectrum. ${ }^{7}$

Effects of the amount of oxygen-containing solvent on the geometric structure were examined using mixtures of anisole and toluene (Figure 3). When anisole was less than $50 \mathrm{vol} \%$, the cis content varied only slightly, and even an amount of anisole as high as $75 \mathrm{vol} \%$ was not enough to provide all-cis polymer.

The cis contents of polymers obtained with the $\mathrm{M}(\mathrm{CO})_{6}-\mathrm{CCl}_{4}-h v$ catalysts were somewhat higher than those with the corresponding metal chlorides in carbon tetrachloride (Table III, No. 1 and 3; Table IV, No. 3). Increases in cis content remained within $10 \%$ even though, in place of carbon tetrachloride, its 1:1 mixtures with oxygen-containing solvents were used for the $\mathrm{M}(\mathrm{CO})_{6}-\mathrm{CCl}_{4}-h v$ system.

In a previous paper, ${ }^{6}$ we reported that some bands in the IR spectrum of poly( $t$-butylacetylene) changed in accordance with the cis content evaluated by ${ }^{13} \mathrm{C}$ NMR. In subsequent studies, however, no such absorptions could be found. These bands might have been due to impurities present in the polymer samples.

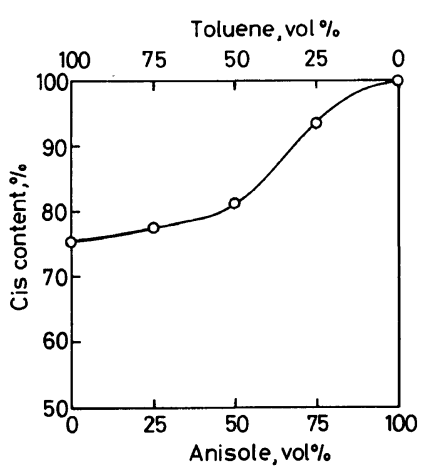

Figure 3. Dependence of the cis content of poly(tbutylacetylene) on solvent composition. (anisole and toluene; $\mathrm{MoCl}_{5}$ ) 
Cis-Trans Thermal Isomerization. To gain an understanding of the relative stability of $c i s$ and trans structures, the thermal isomerization of poly( $t$-butylacetylene) was examined. A polymer sample containing $50 \%$ cis was dissolved in decalin and heated at $160^{\circ} \mathrm{C}$ for $24 \mathrm{~h}$ under nitrogen. Consequently, the cis content increased by about $10 \%$, and the polymer molecular weight decreased slightly. This indicates that the cis structure is more stable than trans. This contrasts with the fact that polyacetylene $^{16}$ and poly(phenylacetylene) ${ }^{3}$ thermally isomerize from cis to trans, the latter being more stable. The bulky $t$-butyl group seems responsible for the unusual relative stability (cis $>$ trans) and, in turn, isomerization (trans to cis) of poly( $t$-butylacetylene). At temperatures above $180^{\circ} \mathrm{C}$ considerable polymer decomposition occurred besides isomerization. No observable isomerization took place below $100^{\circ} \mathrm{C}$ over long periods of time.

Mechanism of Geometric Structure Control. The extremely high cis contents of poly $(t$-butylacetylene)s obtained in oxygen- or nitrogen-containing solvents (Tables I and II) can be interpreted by using a model proposed by Katz et al.

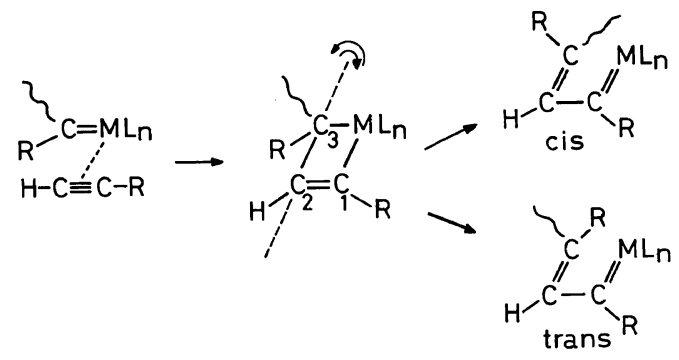

Scheme I.

(Scheme I): The present polymerization is thought to proceed via metal carbene and a metallacyclobutene intermediate ${ }^{5,17}$ that forms from a polymeric metal carbene $\left(\sim \mathrm{CR}=\mathrm{ML}_{n}\right)$. In the second step of Scheme I, the metallacyclobutene undergoes ring scission (cleavage of the $\mathrm{C}_{3}$-metal linkage), during which the $\mathrm{C}_{3}-\mathrm{C}_{2}$ bond rotates around its axis to form a coplanar double bond. Katz et al. ${ }^{7}$ proposed that the geometric structure of polymer is determined by the direction of this rotation; the $\mathrm{C}_{3}-\mathrm{C}_{2}$ bond should rotate in such a way as to minimize the steric interaction between the coordinated metal $\left(\mathrm{ML}_{n}\right)$ and substituent $\mathrm{R}$ or the polymer backbone.
When oxygen- or nitrogen-containing solvents are used, they coordinate to the catalyst metal (the coordination might be loose and reversible, since the catalyst is active enough). The coordinated active center should be bulky and susceptible to steric effect as compared with an uncoordinated one. The result of thermal isomerization (see above) suggests that the $t$-butyl group exerts a greater steric effect than does the polymer chain. For such a bulky substituent, the rotation by which the substituent recedes from the coordinated active center will be favorable to minimize steric hindrance. Eventually, a cis polymer tends to form in coordinating solvents.

$\mathrm{MoCl}_{5}$ can give perfectly cis poly $(t$-butylacetylene), while $\mathrm{WCl}_{6}$ cannot. A possible reason for this is that the atomic radius of molybdenum is shorter than that of tungsten, and therefore the interaction of the Mo-bearing active center with $t$ butyl groups is greater.

Acknowledgments. The authors wish to thank Professor Riichiro Chûjô of Tokyo Institute of Technology for his helpful comments on the assignment of ${ }^{13} \mathrm{C}$ NMR signals. Thanks are also due to Dr. Takeji Hashimoto of this department for making the X-ray diffraction analysis. This research was supported by a Grant-in-Aid for Scientific Research (No. 56550646) from the Ministry of Education, Science and Culture of Japan.

\section{REFERENCES}

1. T. Masuda, M. Kawasaki, Y. Okano, and T. Higashimura, Polym. J., 14, 371 (1982).

2. T. Ito, H. Shirakawa, and S. Ikeda, J: Polym. Sci., Polym. Chem. Ed., 12, 11 (1974).

3. C. I. Simionescu, Sv. Dumitrescu, and V. Percec, $J$. Polym. Sci., Polym. Symp., No. 64, 209 (1978), and references therein.

4. R. J. Kern, J. Polym. Sci., A-1, 7, 621 (1969).

5. T. Masuda, N. Sasaki, and T. Higashimura, Macromolecules, 8, 717 (1975).

6. T. Masuda, Y. Okano, Y. Kuwane, and T. Higashimura, Polym. J., 12, 907 (1980).

7. T. J. Katz, S. J. Lee, and M. A. Shippey, J. Mol. Catal., 8, 219 (1980).

8. P. D. Bartlett and L. J. Rosen, J. Am. Chem. Soc., 64, 543 (1942).

9. P. J. Kocienski, J. Org. Chem., 39, 3285 (1974).

10. T. Masuda, K.-Q. Thieu, N. Sasaki, and T. Higashimura, Macromolecules, 9, 661 (1976). 
11. P. Krausz, F. Garnier, and J.-E. Dubois, J. Am. Chem. Soc., 97, 437 (1975), and subsequent papers.

12. T. Masuda, Y. Kuwane, K. Yamamoto, and T. Higashimura, Polym. Bull., 2, 823 (1980).

13. T. Masuda, H. Kawai, T. Ohtori, and T. Higashimura, Polym. J., 11, 813 (1979).

14. e.g., Y. Inoue, A. Takahashi, Y. Tokitô, R. Chûjô, and Y. Miyoshi, Org. Magn. Resonance, 6, 487 (1974).

15. R. Chûjô, personal communication.

16. T. Ito, H. Shirakawa, and S. Ikeda, J. Polym. Sci., Polym. Chem. Ed., 13, 1943 (1975).

17. T. J. Katz and S. J. Lee, J. Am. Chem. Soc., 102, 422 (1980). 